\title{
A EVOLUÇÃO DO CONCEITO DE ESTADO DE EXCEÇÃO NO PENSAMENTO CONSTITUCIONAL BRASILEIRO
}

\section{Rafael Gonçalves Mota}

Advogado. Especialista em Processo Penal. Mestrando em Direito Constitucional. Professor da Faculdade Farias Brito e da FA7. rafaelgmota@yahoo.com.br

Sumário: Introdução. 1) Conceito de estado de exceção. 2) Evolução do conceito de estado de exceção nas constituições brasileiras: a. Constituição de 1824; b. Constituição de 1891; c. Constituição de 1934; d. Constituição de 1837; e. Constituição de 1946; f. Constituição de 1967; g. Emenda Constitucional nº. 1 de 1969; h. Emenda Constitucional nº 11 de 1978; i. Constituição Federal de 1988. Conclusão.

Resumo: O Estado de Exceção pode ser entendido como um conjunto de medidas excepcionais adotadas pelo estado diante de situações críticas, onde a estrutura do Estado está ameaçada, bem como quando colocam em risco a paz e o equilíbrio social. As Constituições Brasileiras sempre trouxeram no seu texto previsões de medidas extraordinárias que poderiam ser tomadas quando da necessidade de enfrentamento de momentos críticos e graves. Na época imperial a regulamentação era ainda muito tímida, recebendo um tratamento mais adequado e completo na primeira carta constitucional republicana. Com a Constituição de 1934, e, sobretudo com a de 1937, temos uma mais centralização do poder estatal, concentrados no Poder Executivo, o que representou a previsão de um estado de sítio com cores mais fortes e intensas. A redemocratização vinda com o fim do Governo de Getúlio Vargas em 1945 trouxe uma nova realidade política, caracterizada pela Constituição de 1946, que trouxe um sistema de enfrentamento de crises mais descentralizado, com atuação mista do Poder Legislativo e Executivo. Novo revés democrático veio em 1964, fazendo com que mais uma vez o conceito de estados excepcionais fosse mais forte, invasivo e enfático, conforme o disposto nos textos constitucionais em 1967, e as emendas constitucionais de 1969 e 1978. Com o fim do período militar, nova onda democrática altera o texto constitucional indicando dupla possibilidade de instrumentos excepcionais: o estado de defesa e o estado de sítio. 
Palavras-chave: Democracia; Estado de Exceção; Estado de Defesa; Estado de Sítio; Constituição Brasileira; Evolução Histórica

\section{INTRODUÇÃO}

O Estado como estrutura fundamental para a promoção da paz e do equilíbrio coletivo vê-se em consideráveis momentos de sua evolução histórica as voltas com situações críticas, onde medidas excepcionais devem ser tomadas para o restabelecimento pleno da ordem e da legalidade plena.

Tal raciocínio deve ser contextualizado no cenário ideológico, onde as relações institucionais serão influenciadas pelas escolhas políticas que determinarão como o Estado irá agir para manter a ordem constitucional, bem como o próprio conceito de normalidade e equilíbrio social.

A história brasileira é caracterizada pela alternância relativamente constante de poder, o que estimulava o surgimento de momentos de crises institucionais de variadas matizes e intensidades, mas em muitos momentos com significativo comprometimento da ordem pública e jurídica.

Com isso, desde o período imperial imaginou-se um sistema constitucional de enfrentamento e controle de crises, onde, em diferentes graus o Estado Nacional iria intervir com mais vigor na vida social para recuperar a autoridade plena e controlar o movimento crítico.

Iremos iniciar o estudo pelo período imperial, analisando como a primeira carta constitucional brasileira tratava, ainda que de forma embrionária, o assunto, lançando as primeiras bases normativas sobre a matéria.

Com a chegada da república, no fim do século XIX, o texto constitucional vai aperfeiçoar a figura do estado de sítio, instituindo a responsabilidade pessoal da autoridade que cometer ilegalidades neste período e quase sempre indicando quais seriam as medidas autorizadas durante esse momento. Durante a história republicana esse instituto sofreu significativas modificações de conceitos, especialmente ligados à realidade política do momento.

Finalmente analisaremos o conceito constitucional atual do estado de sítio e de defesa, sobretudo considerando a natureza democrática da carta de 1988 .

\section{Conceito de ESTAdo de EXCEÇão}

O conceito de estado de exceção é imensamente plural, sendo difícil encontrarmos um único significado para tal termo. A doutrina nacional e estrangeira apresenta muitas definições distintas, incluindo nomenclaturas diversas como estado de sítio, estado de emergência, estado de defesa, dentre outros. 
Essa dificuldade é bem definida por Giorgio Agamben (2004, p. 12) que nos ensina:

Entre os elementos que tornam difícil uma definição do estado de exceção, encontra-se, certamente, sua estreita relação com a guerra civil, a insurreição e a resistência. Dado que é o oposto do estado normal, a guerra civil se situa numa zona de indecidibilidade quanto ao estado de exceção, que é a resposta imediata do poder estatal aos conflitos internos mais extremos.

O conceito de situação crítica, aquela que poderia autorizar a utilização de remédio extremo como o estado de exceção é bem vista por GILBERTo BERCOVICI (2004, p. 66), ao afirmar:

A situação excepcional não é, ao contrário do que possa parecer, anarquia ou caos, pois sempre subsiste uma ordem, mesmo que não seja jurídica. Não existe uma norma que possa ser aplicada no caos. O estado de exceção existe para criar a situação na qual o direito poderá valer. A exceção é o caso excluído da norma geral, mas não está fora da relação com a norma.

BobBio ao considerar tal instituto fala do que chama de estado de sítio, não fazendo distinção entre este e outros similares, reforçando a idéia de que não há nenhuma uniformidade entre os conceitos. Com isso afirma (BOBBIO, 2000, p.413):

Com a expressão "Estado de sítio" se quer geralmente indicar um regime jurídico excepcional a que uma comunidade territorial é temporariamente sujeita, em razão de uma situação de perigo para a ordem pública, criado por determinação da autoridade estatal ao atribuir poderes extraordinários às autoridades públicas e ao estabelecer as adequadas restrições à liberdade dos cidadãos.

Em alguns momentos a definição de estado excepcional irá se confundir com o próprio conceito de regime totalitário ou formas equivalentes, isto fica evidente nas palavras de Carl Schmitt (2006, p.7), ao iniciar sua obra Teologia Política, quando afirma que o soberano é quem decide sobre o estado de exceção. $\mathrm{E}$ ainda indica que, ao falar do soberano que, ele decide tanto sobre a ocorrência do estado de necessidade extremo, bem como sobre o que se deve fazer para saná-lo (SCHMITT, 2006, p.8).

Um dos pontos e dificuldade sobre a definição do mencionado instituto está em possuir este um caráter essencialmente dinâmico, normalmente ligado a questões políticas de natureza interna e externa ao cenário nacional, bem como a aspectos ideológicos e jurídicos. 
Nesse sentido comenta Giorgio Agaben (2004, p.130 /131) que:

O estado de exceção é o dispositivo que deve, em última instância, articular, e manter juntos os dois aspectos da máquina jurídico-política, instituindo um limiar de indecidibilidade entre anomia e nomos, entre vida e direito, entre auctoritas e potestas. Ele se baseia na ficção essencial pela qual a anomia sob a forma da auctoritas, da lei vida ou da força-de-lei ainda está em relação com a ordem jurídica e o poder de suspender a norma está em contato direto com a vida. Enquanto os dois elementos permanecem ligados, mas conceitualmente, temporalmente e subjetivamente distintos como na Roma republicana, na contraposição entre o Senado e o povo, ou na Europa medieval, na contraposição entre poder espiritual e poder temporal -, sua dialética embora fundada sobre uma ficção - pode, entretanto, funcionar de algum modo. Mas, quando tendem a coincidir numa só pessoa, quando o estado de exceção em que eles se ligam e se indeterminam torna-se a regra, então o sistema jurídico-político transforma-se em uma máquina letal.

Com isso, percebe-se que o conceito e a utilização destes estados excepcionais devem ser muito bem definidos nos textos constitucionais, para com isso, evitar que os institutos originalmente concebidos para proteger o Estado e a sociedade se tornem meros instrumentos totalitários, com objetivo a satisfazer interesses pessoais.

Ainda na lição de ScHMITT, podemos lembrar que essas situações excepcionais servem para confirmar a regra, ou seja, reforçar o conceito de normalidade política e jurídica. Nas suas palavras o que é normal nada prova, a exceção comprova tudo; ela não somente confirma a regra, mas esta vive de exceção. Na exceção, a força da vida real transpõe a crosta mecânica fixada na repetição (SCHMITT, 2006, p.15).

No presente estudo, optamos por utilizar o conceito de estado de exceção conferido por cada Constituição Brasileira, analisando como essas hipóteses foram trabalhadas nas diversas cartas constitucionais, assim, em cada época o conceito deve ser contextualizado, definido e compreendido.

\section{T2 EVOLUÇÃo do CONCEITO DE ESTADO DE EXCEÇÃO NAS CONSTITUIÇÕES BRASILEIRAS}

O início da presente análise toma como referência a evolução do tratamento constitucional sobre as situações excepcionais pelas quais o Estado pode passar, desde o período imperial até os dias atuais.

Ao analisar a estruturação dos conceitos existentes sobre situações excepcionais vamos perceber que os dispositivos normativos sobre a matéria guardam uma íntima relação como momento histórico e a realidade política existente a época. 


\section{a. Constituição de 1824}

A Constituição de 1824, datada de 25 de março deste ano, irá criar as bases e estruturas do Estado Imperial Brasileiro, determinando como o poder estatal deveria ser empregado e exercido naquele contexto específico do período monárquico.

Ao tratar das situações de crise, percebemos ser intenção do legislador constituinte originário deste momento criar o embrião de um sistema de controle diferenciado nesse momento, porém ainda o faz de forma muito tímida.

Não existe neste texto constitucional uma indicação expressa sobre estado de sítio ou similar. Observamos tão somente que a carta irá trazer duas situações excepcionais onde os direitos e garantias fundamentais podem ser suspensos: rebelião ou invasão de inimigos ${ }^{1}$.

Tal previsão é encontrada no artigo $179, \mathrm{n}^{\circ} .34$ e 35 , da referida carta, que nos indique que:

Art. 179. A inviolabilidade dos Direitos Civis, e Politicos dos Cidadãos Brazileiros, que tem por base a liberdade, a segurança individual, e a propriedade, é garantida pela Constituição do Imperio, pela maneira seguinte.

...omissis

XXXIV. Os Poderes Constitucionaes não podem suspender a Constituição, no que diz respeito aos direitos individuaes, salvo nos casos, e circumstancias especificadas no paragrapho seguinte.

XXXV. Nos casos de rebellião, ou invasão de inimigos, pedindo a segurança do Estado, que se dispensem por tempo determinado algumas das formalidades, que garantem a liberdede individual, poder-se-ha fazer por acto especial do Poder Legislativo. Não se achando porém a esse tempo reunida a Assembléa, e correndo a Patria perigo imminente, poderá o Governo exercer esta mesma providencia, como medida provisoria, e indispensavel, suspendendo-a immediatamente que cesse a necessidade urgente, que a motivou; devendo num, e outro caso remetter á Assembléa, logo que reunida fôr, uma relação motivada das prisões, e d'outras medidas de prevenção tomadas; e quaesquer Autoridades, que tiverem mandado proceder a ellas, serão responsaveis pelos abusos, que tiverem praticado a esse respeito. (grifo nosso)

Em regra era impedido qualquer espécie de limitação no exercício dos direitos individuais reconhecidos constitucionalmente, porém admitia-se restrições apenas em duas hipóteses, quais sejam, rebelião e invasão de inimigos.

\footnotetext{
${ }^{1}$ Aqui devemos lembrar que durante todo o tratamento constitucional do Estado de Exceção não encontraremos um conceito normativo sobre o que deva ser entendido como inimigo, especialmente considerando que a aplicação deste conceito é feita ora numa dimensão externa, ora interna. Com isso, sempre devemos lembrar que a análise do assunto deve ser feita contextualizando-o com a realidade política.
} 
A primeira diz respeito à rebelião interna, ou seja, acontecimento de natureza intestina que venha a comprometer de forma grave a autoridade do estado ou a ordem e a paz sociais. Quanto a segunda hipótese teremos uma dimensão essencialmente externa, ou seja, como ações de inimigos estrangeiros contra o império brasileiro, recém independente.

A iniciativa era legislativa, o que sem dúvida mostra-se relevante ao analisar o momento histórico e a forma através da qual a própria Constituição foi produzida.

Não estando a Assembléia Nacional reunida, poderia o Imperador declarar tal estado excepcional, desde que remetesse imediatamente tal ato ao Poder Legislativo para que este referendasse tão logo fosse possível a medida.

Percebemos ainda características mais do que especiais do regramento constitucional, quando, ao finalizar o inciso XXXV do mencionado artigo, indica que era dever do Executivo enviar a Assembléia à relação das medidas excepcionais tomadas, visando com isso exercer alguma espécie de controle.

\section{b. Constituição de 1891}

A primeira constituição republicana, datada de 24 de fevereiro de 1891, inova na ordem constitucional brasileira ao indicar pela primeira vez a expressão estado de sítio, previsto no art. 80 do texto, vejamos:

Art. 80. Poder-se-á declarar em estado de sítio qualquer parte do território da União, suspendendo-se aí as garantias constitucionais por tempo determinado quando a segurança da República o exigir, em caso de agressão estrangeira, ou comoção intestina (art. 34, nº. 21).

Percebe-se que a Carta de 1891 trouxe as mesmas hipóteses de declaração deste estado excepcional previstas na Constituição Imperial, apenas substituindo a expressão rebellião por comoção intestina, e a indicação de agressão estrangeira no lugar de invasão de inimigos. Apesar da diferença de termos o sentido permanece o mesmo, ou seja, proteger o estado de ações agressivas internas e externas, dotando-lhe de instrumentos fortes o suficiente para conter a situação crítica.

A lógica constitucional para a declaração de tal momento reproduz aquela já indicada no texto imperial, qual seja, a iniciativa cabendo prioritariamente ao legislativo, e apenas nos casos onde este não esteja reunido podendo ser tomada por ato de ofício do Presidente da República, conforme dispõe o art. $80, \S 1^{\circ}$ combinado com o art. $48, \mathrm{n}^{\mathrm{o}} .15^{2}$

\footnotetext{
${ }^{2}$ Art. $80, \S 1^{\circ}$ - Não se achando reunido o Congresso e correndo a Pátria iminente perigo, exercerá essa atribuição o Poder Executivo federal (art. 48, $\mathrm{n}^{\circ}$ 15) e Art 48 - Compete privativamente ao Presidente da República: ...omissis... $15^{\circ}$ ) declarar por si, ou seus agentes responsáveis, o estado de sítio em qualquer ponto do território nacional nos casos, de agressão estrangeira, ou grave comoção intestina (art. $6^{\circ}, \mathrm{n}^{\circ} 3$; $\operatorname{art.~34,~} \mathrm{n}^{\circ} 21$ e art. 80);
} 
Uma característica bem especial do modelo de estado de sítio edificado na Carta de 1891 é que este poderia ser declarado apenas para uma região do país, ou seja, não havia a necessidade de uma declaração nacional, porém em todos os casos era necessário que fosse determinado inicialmente o período no qual o mencionado estado vigoraria.

Neste período constitucional é mantida, ainda que por outra redação, a regra pela qual haveria a responsabilização da autoridade que extrapolasse os limites dos atos, ao indicar no art. $80, \S 4^{\circ}$ que as autoridades que tenham ordenado tais medidas são responsáveis pelos abusos cometidos.

De certa forma, a maior contribuição para a regulamentação da matéria pela Constituição de 1891, foi a indicação expressa das medidas excepcionais que poderiam ser tomadas durante a vigência do ato extraordinário. Tais medidas seriam a detenção em lugar não destinado aos réus de crimes comuns ${ }^{3}$ e o desterro para outros sítios do território nacional. ${ }^{4}$

\section{c. Constituição de 1934}

Após a chamada Revolução de 1930, que trouxe Getúlio Vargas ao poder, inicia-se período absolutamente diferenciado na história brasileira, notadamente marcado por uma crescente centralização política e institucional.

Nos primeiros momentos do novo governo, este se depara com grave situação crítica, qual seja, a chamada revolução constitucionalista de 1932, movimento iniciado no estado de São Paulo que lançou o país num quadro de guerra civil ainda inédito na história republicana brasileira e que tinha como principal bandeira a elaboração de uma nova constituição nacional.

Vencido o movimento revoltoso, o governo Vargas acatou a vontade demonstrada pela população paulista e que encontrava simpatia em outros estados da federação. Com isso, temos a Carta Constitucional de 1934.

Ao tratar as situações excepcionais e críticas esta constituição montou um complexo quadro de regulamentação, onde o texto detalhava de forma minuciosa as medidas que poderiam ser tomadas e em que medida.

Merece destaca importante inovação trazida neste momento constitucional. Temos aqui duas dimensões de estados excepcionais: o estado de sítio e o estado de guerra.

O primeiro é disciplinado no art. 175 do texto constitucional, que dispõe:

Art. 175 - O Poder Legislativo, na iminência de agressão estrangeira, ou na emergência de insurreição armada, poderá autorizar o

\footnotetext{
${ }^{3}$ Art. $\left.80, \S 2^{\circ}, 1^{\circ}\right)$, Constituição de 1891.
}

${ }^{4}$ Art. $\left.80, \S 2^{\circ}, 2^{\circ}\right)$, Constituição de 1891. 
Presidente da República a declarar em estado de sítio qualquer parte do território nacional, observando-se o seguinte.

Apesar de repetir a nomenclatura do texto constitucional anterior no que diz respeito ao estado de sítio, a Constituição de 1934 traz novas hipóteses que autorizam a decretação da medida.

A primeira delas é quando ocorre iminência de agressão estrangeira. Veja que aqui não é necessária a agressão em si, mas somente a iminência, criando um conceito aberto e indeterminado, e conseqüentemente de aplicação jurídica insegura.

Já quanto à segunda hipótese temos a idéia de emergência de insurreição armada, ligada necessariamente a uma dimensão interna, onde a instabilidade pública é causada por ações e acontecimentos internos.

AConstituição de 1934 foi inovadora ao tratar da forma através da qual haveria a declaração do estado de sítio, uma vez que a iniciativa era do Presidente da República ${ }^{5}$, mediante autorização prévia do Poder Legislativo ${ }^{6}$, sendo tal procedimento utilizado igualmente quando da necessidade de renovação deste período 7 .

Outra característica específica desta Carta Constitucional é que havia um limite temporal para esta situação excepcional, já que o art. 175, 1) indicava que não será decretado por mais de noventa dias, podendo ser prorrogado, no máximo, por igual prazo, de cada vez.

A atuação estatal é balizada pelo texto constitucional, que vai indicar quais as medicas que podem ser tomadas para o restabelecimento da ordem e paz sociais, indicando que só eram admitidas as indicadas nos art. 175, 2):

a) desterro para outros pontos do território nacional, ou determinação de permanência em certa localidade;

b) detenção em edifício ou local não destinado a réus de crimes comuns;

c) censura de correspondência de qualquer natureza, e das publicações em geral;

d) suspensão da liberdade de reunião e de tribuna;

e) busca e apreensão em domicílio.

A característica essencial do tratamento dado pelo texto constitucional é o rico detalhamento da situação, especialmente quando vai analisar quais seriam as

\footnotetext{
$\overline{5}$. Art. 56 - Compete privativamente ao Presidente da República: ...omissis....; § 13) decretar o estado de sítio de acordo com o art. 175, § $7^{\circ}$, Constituição de 1934.

${ }^{6}$ Caso o Senado Federal e a Câmara dos Deputados não estejam reunidos, o Presidente da República poderá declarar o Estado de Sítio, porém com aquiescência previa da Seção Permanente do Senado Federal.

${ }^{7}$ Art. $175, \S 9^{\circ}$, Constituição de 1934.
} 
medidas vedadas, especialmente a proibição de permanência em lugar deserto ou insalubre do território nacional, nem desterro para tal lugar, ou para qualquer outro, distante mais de mil quilômetros daquele em que se achava ao ser atingida pela determinação $o^{8}$.

Em até cinco dias o preso com fundamento em uma dessas medidas excepcionais deveria ser apresentado pela autoridade responsável ao juiz comissionado para o caso9.

Seguindo na determinação dos limites de atuação do ente estatal durante o estado de sítio, a Constituição vedava a prisão de algumas autoridades públicas, visando com isso proteger as instituições de um uso indevido das medidas excepcionais ${ }^{10}$.

Relevante destaque merece as indicações constitucionais de que, apesar da existência do estado de sítio, em regra o Estado não poderia vedar a circulação de livros, jornais e demais publicações, desde que fossem submetidas à censura prévia ${ }^{11}$.

Finalizada o estado de exceção todos os efeitos serão $\operatorname{cessados}^{12}$, e eventualmente poderia haver a responsabilização pessoal, nas esferas penal e civil, das autoridades públicas por abusos cometidos, fórmula reproduzida dos textos constitucionais anteriores ${ }^{13}$. Admitia-se igualmente a possibilidade de buscar a tutela jurisdicional para preservação de direitos ${ }^{14}$.

Em paralelo ao estado de sítio a Constituição de 1934 indicava também a possibilidade de utilização do estado de guerra, previsto no art. 161, dispondo que o estado de guerra implicará a suspensão das garantias constitucionais que possam prejudicar direta ou indiretamente a segurança nacional.

Este estado é consideravelmente mais amplo e grave do que o Estado de sítio, não se aplicando as limitações e vedações indicadas no art. 175 do citado texto constitucional quando do tratamento do estado de sítio.

Após a chamada Intentona Comunista ${ }^{15}$, é aprovada a emenda constitucional $\mathrm{n}^{\mathrm{o}} 1$, em 1935, que permitia a equiparação da comoção intestina grave ao estado

\footnotetext{
Art. $175, \S 1^{\circ}$, Constituição de 1934 .

Art. $175, \S 3^{\circ}$, Constituição de 1934.

${ }^{10} \mathrm{O}$ Art. $175, \S 4^{\circ}$ indica quem seriam as autoridades protegidas. São elas: os membros da Câmara dos Deputados, do Senado Federal, da Corte Suprema, do Supremo Tribunal Militar, do Tribunal Superior de Justiça Eleitoral, do Tribunal de Contas e, nos territórios das respectivas circunscrições, os Governadores e Secretários de Estado, os membros das Assembléias Legislativas e dos Tribunais superiores

${ }_{11}$ Art. 175, §5 , Constituição de 1934.

12 Art. 175, §11, Constituição de 1934.

${ }_{13}$ Art. 175, §13, Constituição de 1934.

${ }^{14}$ Art. 175, §14, Constituição de 1934.

15 Movimento pelo qual ficou conhecido a tentativa de golpe contra Getúlio Vargas em novembro de 1935 promovido pela chamada Aliança Nacional Libertadora e comandada pelo Partido Comunista Brasileiro. As ações foram concentradas em principalmente nas cidades de Natal, Rio Grande do Norte e Rio de Janeiro, então Capital Federal.
} 
de guerra, uma vez que este admitia a suspensão de quaisquer garantias e direitos fundamentais que de forma direta ou indireta pudessem colocar em risco a segurança nacional.

\section{d. Constituição de 1937}

O ano de 1937 é marcado pelo golpe de estado promovido e capitaneado por Getúlio Vargas, iniciando um período caracterizado pelo totalitarismo, centralização e limitação de direitos, que passa a história como o Estado Novo.

Para criar as bases jurídicas do novo regime, temos em 10 de novembro do mesmo ano o surgimento de uma nova carta constitucional, outorgada e de forma inspiração autoritária. Tal texto é criação essencialmente de Francisco Campos, então Ministro da Justiça, e vai ter como essência a busca pela centralização política e o desejo de conferir ao Estado um poder uno, forte e contundente.

No tratamento do chamado estado de exceção, ou seja, no modelo institucional para enfrentamento de situações críticas, temos duas espécies de medidas: o estado de emergência e o estado de guerra, previstos no art. 166 da citada Constituição.

$\mathrm{O}$ art. 166 do texto constitucional inicia o capítulo intitulado Da Defesa do Estado, demonstrando de forma efetiva que o desejo fundamental deste dispositivo constitucional é a proteção do ente estatal, objetivo essencial dentro do modelo de estado adotado a partir de 1937.

Dispõe o art. 166 que:

Art. 166. Em caso de ameaça externa ou iminência de perturbacões internas ou existências de concerto, plano ou conspiracão, tendente a perturbar a paz pública ou pôr em perigo a estrutura das instituicões. a segurança do Estado ou dos cidadãos, poderá o Presidente da República declarar em todo o território do País, ou na porção do território particularmente ameaçado, o estado de emergência.

Desde que se torne necessário o emprego das forças armadas para a defesa do Estado, o Presidente da República declarará em todo o território nacional ou em parte dele, o estado de guerra. (grifo nosso)

A complexidade deste artigo nos impõe uma análise pontual e detalhada.

Inicialmente percebemos as duas espécies de situações excepcionais que autorizam a utilização do estado de emergência. A primeira delas é a ameaça externa. Tal hipótese não configura nenhuma novidade no pensamento constitucional brasileiro, uma vez que a preocupação com agressões externas de diferentes matizes sempre esteve presente em nossas cartas constitucionais.

Quanto a segunda situação, esta sim, merece maior análise. Devemos perceber que o texto constitucional indica que é possível a utilização do excepcional estado 
quando da iminência de perturbações internas ou existências de concerto, plano ou conspiração, tendente a perturbar a paz pública ou pôr em perigo a estrutura das instituições, a segurança do Estado ou dos cidadãos.

É impossível não associarmos tal previsão com os acontecimentos da história política nacional quando da elaboração de tal carta constitucional. Destes eventos dois merecem destaque. O primeiro deles é a intentona comunista ocorrida em 1935, onde um levante de natureza militar e inspiração comunista visava desestabilizar o governo, ocupando seu lugar. Tal movimento foi rápida e violentamente sufocado, impondo a morte ou detenção da maioria dos envolvidos.

Outro evento que merece registro por sua direta relação é o chamado Plano Cohen. Trata-se de um falso plano para sacar do poder o Presidente Getúlio Vargas, que serviu de justificativa política para o golpe de 1937, momento de efetiva centralização do poder e instituição definitiva do modelo totalitário de Estado e Vargas.

Esses eventos facilitam o entendimento sobre o disposto no artigo retro mencionado, sobretudo quando ele indica concerto, plano ou conspiração, tendente a perturbar a paz pública ou pôr em perigo a estrutura das instituições, a segurança do Estado ou dos cidadãos.

Outra possibilidade de estado excepcional a disposição do governo era o estado de guerra, caracterizado quando fosse necessária a convocação e o emprego das Forças Armadas para a defesa dos interesses nacionais e do próprio estado.

A iniciativa para impor tal estado era do Presidente da República, independente de manifestação do Legislativo, sendo a atuação deste totalmente alijada no processo conforme rezava o parágrafo único do citado artigo que afirmava que para nenhum desses atos ${ }^{16}$ será necessária à autorização do Parlamento nacional, nem este poderá suspender o estado de emergência ou o estado de guerra declarado pelo Presidente da República.

Tal dispositivo é perfeitamente entendido considerando o momento histórico vivido a época, merecendo destaque as próprias palavras de Francisco Campos ao comentar a atuação do Legislativo afirma que nada acontecia em nenhum parlamento do mundo, porque um parlamento é, precisamente, o lugar onde nada acontece e nada se decide (CAMPOS, 2001, p.34).

O art. 168 da Constituição de 1937 indica quais seriam as medidas excepcionais que poderiam ser tomadas pelo estado. São elas:

a) detenção em edifício ou local não destinados a réus de crime comum; desterro para outros pontos do território nacional ou residência forçada em determinadas localidades do mesmo território, com privação da liberdade de ir e vir;

\footnotetext{
${ }^{16}$ Quando o parágrafo único menciona desses atos faz referência ao estado de emergência e ao estado de guerra.
} 
b) censura da correspondência e de todas as comunicações orais e escritas;

c) suspensão da liberdade de reunião;

d) busca e apreensão em domicílio

Sem qualquer sombra de dúvidas o regramento constitucional previsto na Carta de 37 é o mais radical e totalitário de toda a história constitucional brasileira. Comprovando tal pensamento merece destaque o tratamento dado à possibilidade de responsabilização de membros do Congresso Nacional por atos ligados a planos, ações ou condutas contra o estado.

Previa o art. 169 que:

Art. 169. O Presidente da República, durante o estado de emergência, e se o exigirem as circunstâncias, pedirá à Câmara ou ao Conselho Federal a suspensão das imunidades de qualquer dos seus membros que se haja envolvido no concerto, plano ou conspiração contra a estrutura das instituições, e segurança do Estado ou dos cidadãos. (grifo nosso)

Com isso temos que para responsabilizar qualquer parlamentar por atos contra o Estado o Presidente da República deveria pedir autorização prévia ao Legislativo, através da suspensão as imunidades parlamentares. Somente após isso seria possível impor a devida responsabilização.

Apesar deste potencial prestígio a figura do Legislativo, o texto constitucional previa a seguir regra tipicamente autoritária ao prever no parágrafo $1^{\circ}$ (primeiro) do citado artigo que:

$\S 1^{\circ}$ - Caso a Câmara ou o Conselho Federal não resolva em doze horas ou recuse a licença, o Presidente, se, a seu juízo, se tornar indispensável a medida, poderá deter os membros de uma ou de outro, implicados no concerto, plano ou conspiração, e poderá igualmente fazê-lo, sob a sua responsabilidade, e independentemente de comunicação a qualquer das Câmaras, se a detenção for de manifesta urgência.

Assim caso a Câmara Federal não concedesse a licença pedida ou mesmo não decidisse a matéria poderia o Chefe do Executivo Federal determinar a prisão do parlamentar envolvido, se considerar na sua visão ser essa medida absolutamente excepcional, sem que tenha que comunicar nada ao Legislativo.

A caracterização desde estado como uma situação excepcional é indicada ainda mais pela regra indicada no texto constitucional de que não seria possível levar ao conhecimento do Judiciário eventuais lesões a direito ${ }^{17}$.

\footnotetext{
${ }^{17}$ Art. 170. Durante o estado de emergência ou o estado de guerra, dos atos praticados em virtude deles não poderão conhecer os Juízes e Tribunais, Constituição de 1937.
} 
A restrição aos direitos fundamentais é efetivamente uma das mais profundas na história constitucional brasileira, especialmente motivada pela natureza excepcional do regime implementado em 1937. Prova maior disso é o disposto no art. 171 da citada Carta Constitucional que indica que na vigência do estado de guerra deixará de vigorar a Constituição nas partes indicadas pelo Presidente da República.

Com isso, é o Presidente da República que determinará quais dispositivos constitucionais deixarão de ter eficácia durante aquele momento excepcional, podendo tal ato recair sobre qualquer elemento do texto, inclusive direitos e garantias fundamentais, o que considerando a situação crítica era muito comum e constante.

$\mathrm{O}$ processo e julgamento de crimes praticados durante este estado de emergência deveriam ser submetidos a um rito e a uma justiça especial. Neste contexto podemos citar o chamado Tribunal de Segurança Nacional ${ }^{18}$.

Já no caso de crimes praticados contra a estrutura das instituições, a segurança do Estado e dos cidadãos ${ }^{19}$ durante o estado de guerra o julgamento seria por feito por Tribunais Militares.

\section{e. Constituição de 1946}

Com o fim do governo Getúlio Vargas e o restabelecimento da democracia no Brasil, surgiu a necessidade de um novo texto constitucional que criasse as bases jurídicas no novo Estado, renovando de forma ampla as regras que estruturavam a atuação do ente estatal durante as situações críticas que de alguma forma comprometessem a ordem interna.

Neste período volta-se a utiliza a expressão estado de sítio, abandonando-se as nomenclaturas anteriores.

A iniciativa da decretação do estado de sítio volta ao Legislativo, sendo atribuição do Congresso Nacional $^{20}$. O Presidente da República só poderá decretar tal medida durante o recesso legislativo ${ }^{21}$, porém deverá em seguida convocar imediatamente Congresso Nacional, que em 15 (quinze) dias deveria decidir pela aprovação ou não do ato.

O art. 206 da Constituição de 1946 indicava em que hipóteses era possível a decretação do citado estado excepcional. Tal medida seria tomada nos casos de

\footnotetext{
18 Tribunal de exceção criado em setembro de 1936 e que era ativado sempre que o país estivesse sobre o chamado estado de guerra. Foi responsável pelos julgamentos de muitos que participaram da chamada intentona comunista. Foi extinto em outubro de 1945.

19 Art. 173, Constituição de 1937.

20 Art. 206, Constituição de 1946.

21 Art. 208, Constituição de 1946.
} 
comoção intestina grave ou de fatos que evidenciem estar à mesma a irromper e de guerra externa.

Mais uma vez adota-se a formulação dicotômica que autorizava a medida excepcional, qual seja, situações críticas nas duas principais esferas, quais sejam, a interna e a externa.

Uma das mais importantes disposições previstas na Constituição de 46 tratava da importância da lei que decretava tal medida, reservando à dimensão infraconstitucional a regulamentação da medida. Merece destaque o art. 207, vejamos:

\begin{abstract}
Art. 207. A lei que decretar o estado de sítio, no caso de guerra externa ou no de comoção intestina grave com o caráter de guerra civil estabelecerá as normas a que deverá obedecer a sua execução e indicará as garantias constitucionais que continuarão em vigor. Especificará também os casos em que os crimes contra a segurança da Nação ou das suas instituições políticas e sociais devam ficar sujeitos à jurisdição e à legislação militares, ainda quando cometidos por civis, mas fora das zonas de operação, somente quando com elas se relacionarem e influírem no seu curso.
\end{abstract}

Veja que tal dispositivo faz menção a uma situação de comoção interna grave com caráter de guerra civil, ou seja, relacionando tal ato necessariamente a uma idéia de compulsão interna de gravíssimas conseqüências e efeitos.

As medidas passíveis de serem tomadas durante o estado de sítio são elencadas no art. 209, quais sejam:

Art. 209. Durante o estado de sítio decretado com fundamento em o ${ }^{\circ} I$ do art. 206, só se poderão tomar contra as pessoas as seguintes medidas:

I - obrigação de permanência em localidade determinada;

II - detenção em edifício não destinado a réus de crimes comuns;

III - desterro para qualquer localidade, povoada e salubre, do território nacional.

Parágrafo único - O Presidente da República poderá, outrossim, determinar:

I - a censura de correspondência ou de publicidade, inclusive a de radiodifusão, cinema e teatro;

II - a suspensão da liberdade de reunião, inclusive a exercida no selo das associações;

III - a busca e apreensão em domicílio;

IV - a suspensão do exercício do cargo ou função a funcionário público ou empregado de autarquia, de entidade de economia mista ou de empresa concessionária de serviço público;

V - a intervenção nas empresas de serviços públicos. 
Percebe-se que a indicação das medidas é feita tomando como referência o $\mathrm{n}^{\mathrm{o}}$. I do art. 206, ou seja, na hipótese do estado de sítio ser decretado quando do comprometimento da ordem interna, especialmente pelo cenário de convulsão interna.

Quanto ao tempo de duração do estado de sitio, o prazo de duração deste quando for decretado para a preservação da ordem interna é de no máximo de 30 (trinta) dias, não podendo ser prorrogado cada vez por prazo superior a este. Quando a medida é tomada por motivo de guerra externa, poderá perdurar durante todo o período do conflito externo ${ }^{22}$.

As imunidades parlamentares em regra serão preservas durante a vigência do estado de sítio, só podendo ser limitadas por decisão do Congresso Nacional por voto de no mínimo dois terços dos membros da Câmara dos Deputados ou do Senado Federal ${ }^{23}$.

Finalmente dispõe a Constituição de 1946 que encerrado o período de exceção restarão encerrados os efeitos do estado de sítio $^{24}$, e que qualquer abuso cometido durante o regime excepcional poderá ser levado ao Judiciário ${ }^{25}$.

\section{f. Constituição de 1967}

Após o golpe militar de 1964, a estrutura constitucional brasileira sofreu significativas alterações no sentido, mais uma vez na história política nacional, de trazer ao executivo toda a iniciativa e condução do processo de utilização deste estado excepcional, marcando de forma significativa a centralização política e institucional.

As mudanças iniciais no tratamento normativo do assunto vieram com os Atos Institucionais $\mathrm{n}^{\mathrm{o}} .1 \mathrm{e}^{\mathrm{o}} .2$ ( $\left.\mathrm{AI} \mathrm{n}^{\mathrm{o}} .1 \mathrm{e} 2\right)^{26}$. O primeiro mudou a iniciativa de decretação do Estado de Sítio, retirando do Legislativo e transferindo-a para o Presidente da República ${ }^{27}$.

$\mathrm{O}$ art. 13 do $\mathrm{AI} \mathrm{n}^{\mathrm{o}} .2^{28}$ ampliou o prazo máximo de decretação do Estado de Sítio para 180 (cento e oitenta dias) prorrogável por igual período.

A Constituição de 1967 incorporou algumas dessas alterações, disciplinando a matéria nos arts. 152 e 156.

A iniciativa é confirmada para o Presidente da República, indicando que o estado será decretado no caso de grave perturbação da ordem ou ameaça de sua

\footnotetext{
22 Art. 210, Constituição de 1946.

23 Art. 213, Constituição de 1946.

24 Art. 214, Constituição de 1946.

25 Art. 215, Constituição de 1946.

${ }^{26}$ Francisco Campos, principal autor da Constituição de 1937 auxiliou na redação desses dois Atos Institucionais.

27 Art. 6, Ato Institucional no 1, de 9 de abril de 1964.

${ }^{28}$ O Ato Institucional $\mathrm{n}^{\mathrm{o}} 2$, de 27 de outubro de 1965.
} 
irrupção ou por guerra ${ }^{29}$. Percebemos claramente que este texto constitucional trouxe regras mais abertas e subjetivas. Em primeiro lugar quando existir qualquer perturbação da ordem interna, potencial ou real. Quando a segunda hipótese faz menção apenas a guerra, não necessariamente de natureza externa, compreendendo inclusive um conflito caracterizado como uma guerra civil ou revolucionária.

Previa o texto constitucional que o decreto que instituía o estado excepcional deveria indicar em qual a região que seria aplicado, bem como quem deveria exercer as ações relativas a ele.

O parágrafo $\S 2^{\circ}$ do citado artigo indicava quais as medidas poderiam ser tomadas, são elas:

$\S 2^{\circ}$ - O Estado de sítio autoriza as seguintes medidas coercitivas:

a) obrigação de residência em localidade determinada;

b) detenção em edifícios não destinados aos réus de crimes comuns;

c) busca e apreensão em domicílio;

d) suspensão da liberdade de reunião e de associação;

e) censura de correspondência, da imprensa, das telecomunicações e diversões públicas;

f) uso ou ocupação temporária de bens das autarquias. empresas públicas, sociedades de economia mista ou concessionárias de serviços públicos, assim como a suspensão do exercício do cargo, função ou emprego nas mesmas entidades.

Além dessas medidas, era permitido ao Presidente da República que em casos de ameaça a integridade ou a independência do país poderia tomar outras medidas a serem previstas em $l \mathrm{ei}^{30}$.

O prazo máximo de duração do estado diferenciado seria de 60 (sessenta) dias, prorrogável por igual período. Tal prazo não seria observado no caso da medida ter sido decretava por guerra.

Para a decretação do estado de sítio, mesmo tendo a iniciativa, o Presidente da República, deveria submeter sua vontade ao Congresso Nacional no prazo de 5 (cinco) dias. Caso o Poder Legislativo Federal não estivesse reunido deveria ser convocado. Ainda em relação ao Congresso, as imunidades de seus membros permaneciam, e só poderiam ser suspensas por voto favorável de mais de dois terços dos membros da Casa a que pertencer o congressista ${ }^{31}$.

${ }^{29}$ Art. 152, Constituição de 1967.

${ }^{30}$ Art. 152, $\S 3^{\circ}$, Constituição de 1967 que dispõe: A fim de preservar a integridade e a independência do Pais, o livre funcionamento dos Poderes e a prática das instituições, quando gravemente ameaçados por fatores de subversão ou corrupção, o Presidente da República, ouvido o Conselho de Segurança Nacional, poderá tomar outras medidas estabelecidas em lei.

31 Art. 154, parágrafo único, Constituição de 1967. 
Finalmente com a cessação da situação critica o Presidente da República encaminhará ao Congresso Nacional justificativa as ações, e não existia vedação a busca de tutela jurisdicional em caso de abuso ou limitações.

\section{g. Emenda Constitucional no. 1 de 1969}

A Constituição de 1967 sofreu significativa alteração com a Emenda

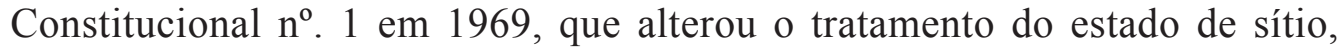
deslocando a regulamentação dos arts. 152 a 156 para os arts.155 a 159.

Algumas modificações existiram especialmente a ampliação do prazo máximo de vigência da medida, de 60 (sessenta) dias para 180 (cento e oitenta) dias ${ }^{32}$. A autorização para o processamento e responsabilização de membro do Congresso Nacional deixa exigir o voto secreto de dois terços dos membros Casa Legislativa, e passa a prever simplesmente deliberação da Casa a que eles pertencerem.

Com a edição do Ato Institucional $n^{\circ} .5$, passamos a ter uma nova realidade política nacional, especialmente caracterizada com imensa concentração de poderes no Executivo, o que tornou se aplicação prática muitas das limitações impostas na norma constitucional.

\section{h. Emenda Constitucional n ${ }^{o} .11$ de 1978}

O ano de 1978 trouxe significativa novidade no tratamento da regra do estado de sítio com a Emenda Constitucional $n^{\circ}$. 11. Neste momento histórico já observamos o início de relativização das ações radicais do Governo, e já se iniciava efetivamente as discussões e movimentos no sentido de redemocratizar o Brasil.

Muitas das medidas adotadas com o Ato Institucional $n^{\circ} .5$ foram revogados, e as hipóteses de decretação e verificação da necessidade de utilização do Estado de Sítio foram alteradas.

O art. 155, com nova redação indica as hipóteses de utilização da medida, in verbis:

Art. 155 - O Presidente da república, para preservar ou, prontamente, restabelecer, em locais determinados e restritos a ordem pública ou a paz social, ameaçadas ou atingidas por calamidades ou graves perturbações que não justifiquem a decretação dos estados de sítio ou de emergência, poderá determinar medidas coercitivas autorizadas nos limites fixados por $\S 2^{\circ}$ do artigo 156 , desde que não excedam o prazo de 60 (sessenta) dias, podendo ser prorrogado uma vez e por igual período.

Art. 156 após a inovação constitucional 
Aqui mais uma vez se utilizam duas expressões distintas, quais sejam, o estado de sitio ou o estado de emergência. A diferença fundamental entre as medidas reside no fato de que o primeiro é direcionado a problemas internos, onde a situação crítica ocorra no cenário intestino. Já o estado de emergência refere-se a problemas ligados a conflitos externos, normalmente de natureza bélica.

O prazo de duração máximo continua sendo de 180 (cento e oitenta) dias, salvo no caso de guerra, uma vez que neste o tempo de duração de situação excepcional é mais indeterminado e impreciso.

\section{i. Constituição de 1988}

Com a redemocratização do país em 1985, uma nova estrutura constitucional era obrigatória, sendo realizada através de Carta Constitucional de 1988. Os novos valores e princípios que passam a reger a realidade política e jurídica brasileira influenciam também o tratamento constitucional do estado de exceção.

Assim, passamos a enxergar no texto constitucional dois institutos distintos para o enfrentamento das situações críticas, quais sejam, o estado de defesa e o estado de sítio ${ }^{33}$.

O estado de defesa poderá ser decretado pelo Presidente da República, depois de ouvidos o Conselho da República e o Conselho de Defesa Nacional, desde que tenha como objetivo preservar ou prontamente restabelecer, em locais restritos e determinados, a ordem pública ou a paz social ameaçadas por grave e iminente instabilidade institucional ou atingidas por calamidades de grandes proporções na natureza.

A decretação do estado de defesa é atribuição do Presidente da República, que deverá submeter tal decisão ao Congresso Nacional, que se não estiver reunido irá ser convocado. Rejeitado o pedido, cessa o estado.

$\mathrm{O}$ decreto que determinar a utilização do estado de defesa especificará o tempo de duração da medida (que não poderá ser superior a trinta dias, podendo ser prorrogado por mais uma vez se os fundamentos continuarem existindo ${ }^{34}$ ) bem como a área de atuação do mesmo ${ }^{35}$. Poderão ser utilizadas quaisquer das seguintes condutas:

I - restrições aos direitos de:

a) reunião, ainda que exercida no seio das associações;

b) sigilo de correspondência;

c) sigilo de comunicação telegráfica e telefônica;

\footnotetext{
${ }^{33}$ Arts. 136 a 141 da Constituição Federal de 1988.

${ }^{34}$ Art. 136, § 2 ${ }^{\circ}$, Constituição de 1988.

${ }^{35}$ Art. 136, § 1 ${ }^{\circ}$, Constituição de 1988.
} 
II - ocupação e uso temporário de bens e serviços públicos, na hipótese de calamidade pública, respondendo a União pelos danos e custos decorrentes.

Qualquer prisão durante a vigência do estado deverá ser comunicada a autoridade judicial competente, que deverá ser relaxada quando for ilegal ${ }^{36}$. As prisões ou detenções feitas não poderão durar mais de 10 (dez) dias, salvo com autorização judicial expressa ${ }^{37}$. A incomunicabilidade do preso é vedada, tornando com isso não recepcionado o dispositivo do Código de Processo Penal que dispunha tal mandamento ${ }^{38}$.

O estado de sítio tem suas hipóteses de cabimento no art. 137 da Constituição de 1988, especialmente caracterizadas por situações críticas de natureza interna e externa. Reza o art. 137 que:

Art. 137. O Presidente da República pode, ouvidos o Conselho da República e o Conselho de Defesa Nacional, solicitar ao Congresso Nacional autorização para decretar o estado de sítio nos casos de:

I - comoção grave de repercussão nacional ou ocorrência de fatos que comprovem a ineficácia de medida tomada durante o estado de defesa;

II - declaração de estado de guerra ou resposta a agressão armada estrangeira.

Mais uma vez observamos que o texto constitucional admite a utilização deste sistema excepcional por problemas internos na realidade nacional que comprometam a ordem pública ou a paz coletiva ou diante da ocorrência de problemas de natureza externa ligadas a conflitos bélicos.

O decreto que institui o estado de sítio determinará qual a duração da medida, bem como quais as garantias constitucionais que ficarão suspensas. Interessante observar que diante da indicação do texto de limitação de garantias, e fazer menção só aquelas, não poderemos imaginar em tese limitação de direitos.

Necessário fazer menção as medidas que podem ser tomadas durante a vigência do estado excepcional, indicas no art. 139, que nos indica:

Art. 139. Na vigência do estado de sítio decretado com fundamento no art. 137, I, só poderão ser tomadas contra as pessoas as seguintes medidas:

I - obrigação de permanência em localidade determinada;

II - detenção em edifício não destinado a acusados ou condenados por crimes comuns;

\footnotetext{
${ }^{36}$ Art. 136, § $3^{\circ}$, I, Constituição de 1988.

${ }^{37}$ Art. 136, § $3^{\circ}$, III, Constituição de 1988.

${ }^{38}$ Art. 136, § 3 ${ }^{\circ}$, IV, Constituição de 1988.
} 
III - restrições relativas à inviolabilidade da correspondência, ao sigilo das comunicações, à prestação de informações e à liberdade de imprensa, radiodifusão e televisão, na forma da lei;

IV - suspensão da liberdade de reunião;

V - busca e apreensão em domicílio;

VI - intervenção nas empresas de serviços públicos;

VII - requisição de bens.

Parágrafo único. Não se inclui nas restrições do inciso III a difusão de pronunciamentos de parlamentares efetuados em suas Casas Legislativas, desde que liberada pela respectiva Mesa.

Durante todo o desenvolvimento das medidas que caracterizam o estado de defesa ou de sítio, haverá a fiscalização das ações pelo Congresso Nacional, que irá determinar uma comissão para fazer o tal controle ${ }^{39}$.

\section{Conclusão}

Após a análise do tratamento constitucional do estado de exceção podemos concluir que a definição normativa deste tem intima ligação com a realidade política vigente à época, especialmente quanto ao modelo de estruturação do poder do estado, se totalitário ou democrático.

Percebemos que a necessidade de limitação de direitos e garantias constitucionais sempre foi visto como um instrumento necessário para promover o restabelecimento da paz e equilíbrio social.

Outro ponto relevante de conclusão está ligado competência para a decretação do estado excepcional, pois de acordo com a intensidade de centralização do poder público a iniciativa alterna-se entre o Presidente da Republico e o Congresso Nacional.

Podemos concluir que a proteção estatal e social com meios mais fortes de atuação do Estado é fundamental, uma vez que possuir um modelo constitucional mais enfático de enfrentamento de situações críticas é indispensável para a manutenção do estado de direito, especialmente dentro de um cenário constitucional.

Por fim devemos lembrar que a criação e utilização de um modelo constitucional de estado de exceção dentro de um cenário democrática, ao contrário de um potencial paradoxo, gera é a confirmação da regra, ou seja, como estruturalmente podemos fortalecer a atuação do Estado para a preservação e proteção das instituições democráticas.

${ }^{39}$ Art. 140, Constituição de 1988. 


\section{REFERÊNCIAS}

AGABEM, Giorgio. Estado de Exceção. São Paulo: Boitempo, 2004.

BERCOVICI, Gilberto. Constituição e Estado de Exceção Permanente. Rio de Janeiro: Azougue, 2004.

BOBBIO, Norberto. Dicionário de Política. Brasília: Universidade de Brasília, 2000.

BRASIL, Constituição (1824). Constituição de 1824, Brasília, DF, Senado, 2000.

. Constituição (1891). Constituição de 1891, Brasília, DF, Senado, 2000.

. Constituição (1834). Constituição de 1934, Brasília, DF, Senado, 2000.

. Constituição (1837). Constituição de 1937, Brasília, DF, Senado, 2000.

. Constituição (1846). Constituição de 1946, Brasília, DF, Senado, 2000.

. Constituição (1867). Constituição de 1967, Brasília, DF, Senado, 2000.

. Constituição (1888). Constituição de 1988, Brasília, DF, Senado, 2007.

CAMPOS, Francisco. O Estado Nacional: sua estrutura, seu conteúdo ideológico. Brasília: Senado Federal, 2001.

GUIMARÃES, Marcello Ovídio Lopes. Tratamento Penal do Terrorismo. São Paulo: Quartier Latin, 2007.

SCALQUETTE, Ana Cláudia Silva. Sistema Constitucional das Crises. Porto Alegre: Sérgio Antônio Fabris, 2004

SCHMITT, Carl. Teologia política. Belo Horizonte: Del Rey, 2006.

THEEVOLUTIONOFTHECONCEPTOF STATEOF EXCEPTION ACCORDING TO BRAZIL'S CONSTITUTIONAL DOCTRINE

Abstract: The state of exception can be understood as a set of extreme measures adopted by the state during critical situations, when the state's structure is threatened just as when the peace and social order are in serious danger. The Brazilian constitutions have always established textually the possibility of extraordinary measures that can be taken when the need of confronting critical situations is identified. In imperial times the regulation of the matter was still very timid and received a more accurate and complete treatment on the first republican constitutional letter. In the constitution of 1934 and, especially in the following one, in 1937, we can find a strong centralization of state power, concentrated on the Executive, which represented the possibility 
of state of emergency in stronger and more intense colors. The re-democratization, that began in 1945, right after the Vargas Government, brought a new political reality symbolized in the 1946 constitution, which established a system of crisis confrontation a lot more decentralized, with the participation of both the Executive and the Judiciary. A new democratic reverse came in 1964 turning the concept of exceptional states stronger and more invasive again, as it was established by the constitutional text in 1967 and the constitutional amendments of 1969 and 1978. At the end of the military period, a new democratic environment changed the constitution text and set two different possibilities of exceptional instruments: the state of defense and the state of emergency.

Key words: Democracy. State of emergency. State of exception. Brazilian constitution. History. 